\title{
The HCL gene of Medicago truncatula controls Rhizobium-induced root hair
}

\section{curling}

\author{
Romy Catoira ${ }^{1}$, Antonius C. J. Timmers ${ }^{1}$, Fabienne Maillet ${ }^{1}$, Christine Galera ${ }^{1}$, R. Varma Penmetsa ${ }^{2}$, \\ Douglas Cook ${ }^{2, \ddagger}$, Jean Dénarié ${ }^{1}$ and Clare Gough ${ }^{1, *}$
}

${ }^{1}$ Laboratoire de Biologie Moléculaire des Relations Plantes-Microorganismes, CNRS-INRA UMR215, BP27, 31326 Castanet-

Tolosan Cedex, France

2Department of Plant Pathology and Microbiology, Crop Biotechnology Centre, Texas A\&M University, College Station, TX 77843, USA

ҒPresent address: Department of Plant Pathology, University of California, Davis, CA 95616-8680, USA

*Author for correspondence (e-mail: gough@toulouse.inra.fr)

Accepted 13 February; published on WWW 5 April 2001

\section{SUMMARY}

The symbiotic infection of the model legume Medicago truncatula by Sinorhizobium meliloti involves marked root hair curling, a stage where entrapment of the microsymbiont occurs in a chamber from which infection thread formation is initiated within the root hair. We have genetically dissected these early symbiotic interactions using both plant and rhizobial mutants and have identified a $M$. truncatula gene, $H C L$, which controls root hair curling. S. meliloti Nod factors, which are required for the infection process, induced wild-type epidermal nodulin gene expression and root hair deformation in $\mathrm{hcl}$ mutants, while Nod factor induction of cortical cell division foci was reduced compared to wild-type plants. Studies of the position of nuclei and of the microtubule cytoskeleton network of $h c l$ mutants revealed that root hair, as well as cortical cells, were activated in response to $S$. meliloti. However, the asymmetric microtubule network that is typical of curled root hairs, did not form in the mutants, and activated cortical cells did not become polarised and did not exhibit the microtubular cytoplasmic bridges characteristic of the pre-infection threads induced by rhizobia in $M$. truncatula. These data suggest that hol mutations alter the formation of signalling centres that normally provide positional information for the reorganisation of the microtubular cytoskeleton in epidermal and cortical cells.

Key words: Symbiosis, Microtubular cytoskeleton, Infection process, Positional signalling, Medicago truncatulata, Rhizobia

\section{INTRODUCTION}

Legumes are able to establish a symbiotic interaction with bacteria of the genera Rhizobium, Bradyrhizobium, Azorhizobium, Mesorhizobium and Sinorhizobium, collectively referred to as rhizobia. This interaction involves two processes, a controlled infection and the induction of a new plant organ, the nodule, in which nitrogen fixation occurs (Mylona et al., 1995; Long, 1996; Schultze and Kondorosi, 1998).

The interaction between host plants and rhizobia begins with a molecular dialog in the rhizosphere. Flavonoids secreted by the plant root induce the expression of the bacterial nodulation (nod) genes, which encode proteins involved in the synthesis and secretion of lipochito-oligosaccharidic bacterial symbiotic signals called Nod factors (NFs) (Dénarié et al., 1996; Downie, 1998). Purified NFs are able to initiate in host plants, the developmental program leading to nodule formation, inducing responses such as root hair deformations, cortical cell divisions (Ccd) and the expression of specific plant genes called early nodulin genes (Hadri and Bisseling, 1998; Downie and Walker, 1999).
The infection process (Kijne, 1992; Brewin, 1998), shows a high degree of host-plant specificity (Dart, 1977), and requires NFs (van Brussel et al., 1992; Ardourel et al., 1994). In most legumes, bacteria initiate the infection of host roots by eliciting the marked curling of root hairs (shepherd's crooks). Inside the curled root hair, bacteria are trapped between appressed cell walls (Callaham and Torrey, 1981; Wood and Newcomb, 1989), and this appears as a typical structure forming a hyaline spot. From here, rhizobia then initiate the formation of infection threads, which are inward tip-growing tubular structures, by a localised degradation of the modified cell wall and invagination of the plasma membrane (Callaham and Torrey, 1981; Ridge and Rolfe, 1985). Concomitantly to infection thread growth, inner cortical cells are mitotically activated and begin to divide, giving rise to the nodule primordium (Timmers et al., 1999). Infection threads grow inside root hairs and penetrate cortical cells at the site where cytoplasmic bridges, called preinfection threads (PITs), are located (van Brussel et al., 1992; Van Spronsen et al., 1994). Infection threads subsequently ramify and bacteria are released in nodule primordium cells, 
where they differentiate into bacteroids which fix nitrogen (Brewin, 1998). Reorganisation of the host microtubular cytoskeleton occurs in epidermal and cortical cells during early stages of infection (Bakhuizen 1998; Van Brussel et al., 1992; Timmers et al., 1999).

While it is known that the host plant determines the site of nodule primordium formation, the mode of invasion (Dart, 1977) and the site of infection thread penetration in cortical cells (van Brussel et al., 1992), little is known concerning the plant's genetic control of these processes. Using Medicago truncatula we have started to genetically dissect the infection process and the mechanisms that underlie rhizobial-induced modifications of the host cytoskeleton. In this work, genetic and cellular analyses of ethylmethane sulfonate (EMS) mutants of M. truncatula (Penmetsa and Cook, 2000), enabled us to identify a $M$. truncatula gene, called HCL (for hair curling), which controls Rhizobium-induced root hair curling. Purified NFs induced epidermal responses in $h c l$ mutants similar to those induced in wild-type plants. However, mutations in $H C L$ altered both the asymmetric reorganisation of the microtubule cytoskeleton (MtC) in root hairs and the polarisation of outer cortical cells, i.e. the re-orientation of the MtC network to form pre-infection threads, in the presence of Sinorhizobium meliloti.

\section{MATERIALS AND METHODS}

\section{Bacterial strains and plants}

Bacterial strains and plants are described in Table 1. Bacterial and plant growth conditions have been described previously (Truchet et al., 1985; Catoira et al., 2000).

\section{Genetic analysis of plants}

Screening for $\mathrm{Nod}^{-} M$. truncatula mutants, crosses and nodulation assays were as described previously (Catoira et al., 2000).

\section{Assays for Nod factor responses}

NFs were prepared as described previously (Roche et al., 1991). Root hair deformation assays were performed as described previously
(Catoira et al., 2000). Mutants were crossed to transgenic lines of $M$. truncatula Jemalong expressing fusions between the reporter gene encoding $\beta$-glucuronidase (GUS) and the MtENOD11 or the MtENOD12 promoters, as described previously (Catoira et al., 2000) and seedlings of transgenic mutant lines were tested with NFs (Catoira et al., 2000). Plants were grown and treated with NFs, then used for RT-PCR, as described previously (Catoira et al., 2000), with rip1 cDNA being amplified with forward primer 5'-GGCCCTGTTGTATCTTGTGC-3' and reverse primer 5'-GTCGAATCTCGCCTTGT$3^{\prime}$. The protocol for the Ccd assay was kindly provided by P. Gamas. Seedlings were grown in growth pouches (Catoira et al., 2000) and NFs added when secondary roots were developing, 8-10 days after transfer into pouches. Roots were collected 14 days after NF treatment and fixed with $2.5 \%$ glutaraldehyde in $0.2 \mathrm{M}$ sodium cacodylate, $\mathrm{pH}$ 7.2 .

\section{Immunolocalisation of microtubules}

For in situ localisation of $\alpha$-tubulin, 7-day old plants were spot inoculated with $0.3 \mu \mathrm{l}$ of a bacterial suspension in water, at $10^{8}$ bacteria/ml, on the root hair emergence zone and samples collected after 2, 4 or 7 days. $\alpha$-tubulin localisation was determined as described previously (Timmers et al., 1999), except that samples were fixed with $2.5 \%$ glutaraldehyde in $0.2 \mathrm{M}$ sodium cacodylate, $\mathrm{pH}$ 7.2. A minimum of ten plants were sectioned for each time point.

\section{Microscopic methods}

For infection studies, plants were inoculated with strains carrying the plasmid pXLGD4 (Table 1), fixed after 3, 5 or 7 days and stained for $\beta$-galactosidase activity as described previously (Ardourel et al., 1994). To visualise root hair deformations, roots were subsequently stained with $0.002 \%$ Methylene Blue, then observed by light microscopy. Five to ten plants were used at each time point, and each experiment was repeated at least twice. Plants were treated with sodium hypochlorite $\left(12^{\circ}\right)$ for 3 minutes, rinsed, immersed in $0.002 \%$ Methylene Blue and mounted in $0.1 \mathrm{M}$ potassium iodide before being observed by light microscopy for Ccd. For light microscopy, plants were observed with a Zeiss Axiophot I or an Olympus Vanox microscope. Transgenic plants were observed with a stereomicroscope (Leica MZ6). Sections stained for $\alpha$-tubulin were viewed by light microscopy using Normaski optics, then by fluorescence microscopy (Zeiss, Axiophot 2) or confocal laser scanning microscopy (Zeiss, LSM 410 invert), as described previously (Timmers et al., 1999).

Table 1. Bacterial strains, plasmids and plants used in this study

\begin{tabular}{|c|c|c|}
\hline Designation & Relevant characteristics & Reference/source \\
\hline \multicolumn{3}{|l|}{ S. meliloti } \\
\hline ABS7 & $\mathrm{Nod}^{+} \mathrm{Fix}^{+}$on M. truncatula & Bekki et al., 1987 \\
\hline GMI6526 & 2011(pXLGD4), $\mathrm{Nod}^{+} \mathrm{Fix}^{+}$on M. truncatula & Ardourel et al., 1994 \\
\hline GMI6630 & $2011 \Delta($ nodF) 13 nodL::Tn5(pXLGD4) & Ardourel et al., 1994 \\
\hline GMI3125 & $2011 \Delta(\operatorname{nodF}) 13$ nodL::Tn5 nodC::Spc & Catoira et al., 2000 \\
\hline GMI3198 & 2011(pGMI3194)(pXLGD4) & Catoira et al., 2000 \\
\hline GMI6702 & 2011 nodA::Tn5\#2208(pXLGD4) & Debellé et al., 1986 \\
\hline pGMI1394 & pML132-prime (IncQ) carrying nodD1 of S. meliloti, Gen ${ }^{\mathrm{R}}$ & Demont et al., 1994 \\
\hline pMH682 & pWB85a prime (IncP), carrying nodD 3 and $s y r M$ of $S$. meliloti, $\mathrm{Tc}^{\mathrm{R}}$ & Honma et al., 1990 \\
\hline \multicolumn{3}{|l|}{ Medicago truncatula } \\
\hline Jemalong A17 & Wild-type, $\mathrm{Nod}^{+} \mathrm{Fix}^{+}$with S. meliloti & Penmetsa and Cook, 1997 \\
\hline Jemalong (MtENOD11-GUS) & Jemalong A17 carrying a MtENOD11-GUS fusion construct & $\begin{array}{l}\text { D. G. Barker, J. L. Pingret, M. Chabaud and E. P. } \\
\text { Journet, unpublished results }\end{array}$ \\
\hline Jemalong (MtENOD12-GUS) & Jemalong A17 carrying a $M t E N O D 12-G U S$ fusion construct & Pingret et al., 1998 \\
\hline
\end{tabular}




\section{RESULTS}

\section{A new phenotypic class of infection-defective mutants of Medicago truncatula}

The aim of this work was to characterise mutants that were blocked early for infection, but that were still responsive to NFs. We therefore looked for mutants defective in shepherd's crook $\left(\mathrm{Hac}^{-}\right)$and infection thread $\left(\mathrm{Inf}^{-}\right)$formation, but which showed root hair deformations in the presence of Sinorhizobium meliloti, a characteristic sign of NF responsiveness (Lerouge et al., 1990). Following large scale EMS mutageneses of Medicago truncatula Jemalong (Penmetsa and Cook, 2000), a two stage screen was performed: (1) a visual screen of $\mathrm{M}_{2}$ plants following inoculation with the wild-type $S$. meliloti strain ABS7 (Table 1) for mutants with no nodules and no bumps $\left(\mathrm{Nod}^{-}\right)$on their roots, but having wild-type shoot and root systems, and (2) microscopic observation of roots of $\mathrm{M}_{3}$ plants, for the presence of root hair deformations and the absence of infection-related events. For this, seedlings were inoculated with S. meliloti GMI6526, which carries a constitutively expressed lac $Z$ gene (Table 1), and stained for $\beta$-galactosidase activity to detect bacteria, and with Methylene Blue to visualise root hair deformations.

Three Nod $^{-}$mutants, B56, W1 and AF3, were selected as showing abundant root hair deformations. In contrast to wild-type plants, which showed marked curling with a refractile spot, characteristics of the $\mathrm{Hac}^{+}$phenotype, and infection threads (Fig. 1A-C), neither of these phenotypes were observed in any of the mutants despite exhaustive observation. Bacterial colonisation and attachment were evident, however, on root hairs and the epidermis of mutants from staining for bacterial $\beta$-galactosidase, even after bleach clearing (data not shown). The root hair deformations exhibited by the three mutants included branching and swelling of root hair tips (Fig. 1D). Root hairs of $\mathrm{W} 1$, and less frequently $\mathrm{AF} 3$, also showed 'continuous root hair curling' (Fig. $1 \mathrm{E})$, which differed in two ways from the Hac phenotype; (1) root hairs curled much more extensively (compare Fig. 1C and 1E) and (2) no bacteria were visible within the curled root hairs. In wild-type plants, root hairs that responded to $S$. meliloti were detected in a limited zone of the root, while the three mutants showed a larger responsive zone in which root hairs were characteristically deformed and longer. This indicates that root hair deformation continues, unlike in wild-type plants, where there is transient susceptibility to Rhizobium.

To exclude the possibility that these mutants were $\mathrm{Nod}^{-}$due to their inability to induce rhizobial NF production, we verified that $S$. meliloti GMI6390 (Table 1), a strain that constitutively overproduces NFs, was unable to nodulate B56, W1 and AF3 (data not shown). Subsequently we used a $S$. meliloti strain, GMI3198, which carries both the regulatory gene nodD1 for overproduction of NFs in response to plant-secreted flavonoids,
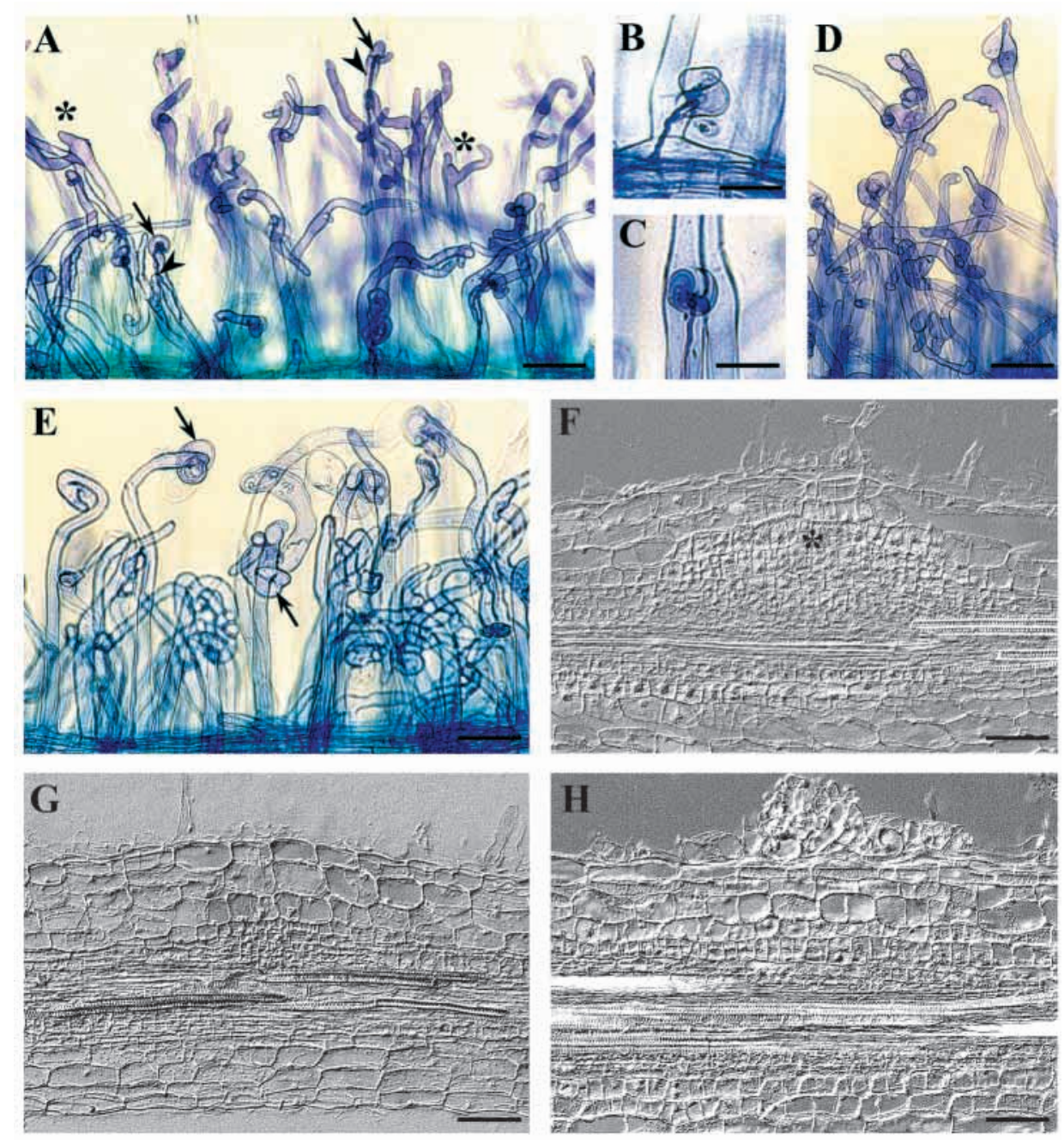

Fig. 1. Root hair deformations and cortical cell division in response to S. meliloti. (A-E) Root hairs stained for $\beta$-galactosidase activity (to visualise bacteria) and post-stained with Methylene Blue, 7 days after inoculation with $S$. meliloti GMI6526. (A) Wild-type M. truncatula, showing formation of shepherd's crooks (Hac; arrows) and infection threads (Inf; arrowheads) and deformed root hairs with sub-apical branches (asterisks). Bar, $100 \mu \mathrm{m}$. (B, C) Close-ups of Hac in wild-type root hairs. Bars, $50 \mu \mathrm{m}$. (D) B56, showing root hair deformations, including subapical branching and swollen tips, but no Hac. Bar, $100 \mu \mathrm{m}$. (E) W1, showing root hair deformations, including 'continuous curling' (arrows), but no Hac as evidenced by the absence of both a hyaline spot and bacterial entrapment in the centre of the curls. Bar, $75 \mu \mathrm{m}$.

(F-H) Root sections made 4 days after inoculation with $S$. meliloti GMI6526 viewed with Nomarski optics. Bars, $80 \mu \mathrm{m}$. (F) Wild type, showing extensive cortical cell divisions (Ccd) and a meristem (asterisk). (G) B56, showing Ccd limited to the inner cortex. (H) W1, showing greater cortical mitotic activity than B56 (compare with G), but lower than in the wild type (compare with F) and no meristem. 
A

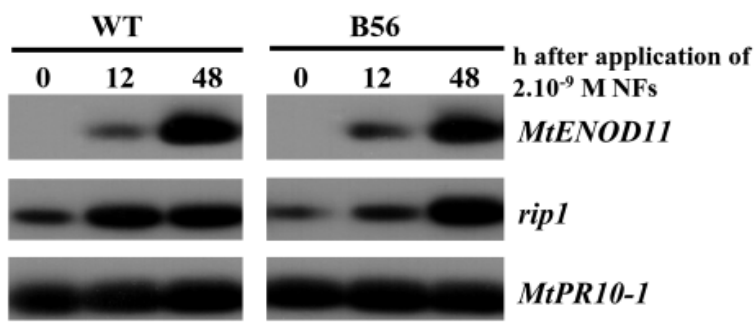

B
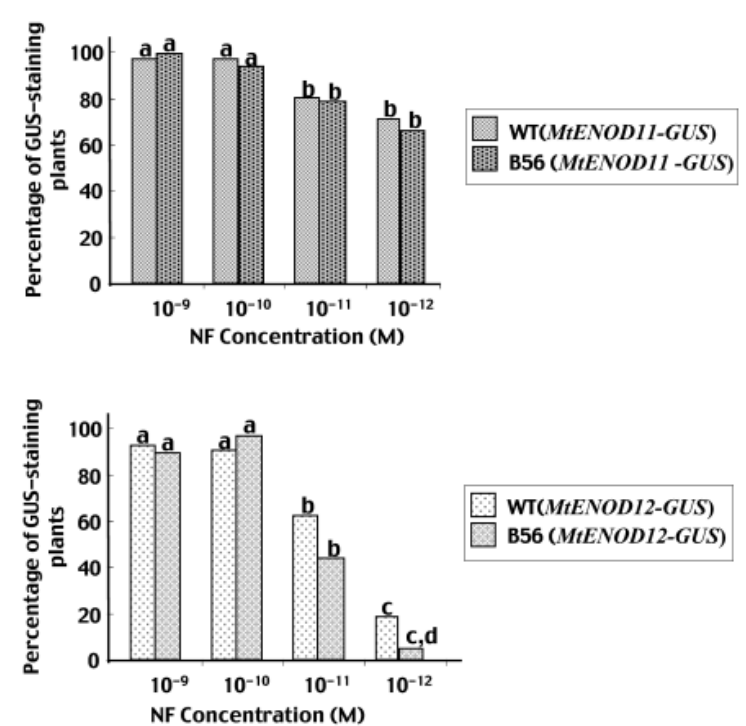

Fig. 2. Analysis of early nodulin gene expression in response to Nod factors (NFs). (A) RT-PCR analysis of MtENOD11 and ripl expression in wild-type (WT) and B56 roots in response to NFs. MtPR10-1 RNA was amplified as a control for the quality and quantity of RNA. (B) Effect of different NF concentrations on MtENOD11-GUS and MtENOD12-GUS expression in transgenic lines of wild type (WT) and B56. At least two independent experiments were performed on 15-20 plants/sample, scored 6 hours after treatment with NFs. Values with different letters differ significantly $(P=0.05)$. Analysis of variance was conducted separately for MtENOD11 and MtENOD12 using Fisher's Exact test (Kendall and Stuart, 1976).

and a constitutively expressed lacZ reporter gene for bacterial visualisation (Table 1). Following inoculation of B56, W1 and AF3 by GMI3198, no shepherd's crooks or infection threads were seen, although root hair deformations were enhanced (both in terms of numbers of root hairs deformed and in the deformations themselves), compared to when plants were inoculated with the wild-type $S$. meliloti strain GMI6526 (data not shown). When mutants were inoculated with GMI3125, a S. meliloti strain unable to produce NFs (Table 1), no root hair deformations could be seen, confirming that their induction is dependent on NFs (data not shown).

In wild-type Medicago plants, rhizobia induce cortical cell divisions (Ccd) prior to Hac formation (Timmers et al., 1999). Purified NFs alone can also induce $\mathrm{Ccd}$ and thus, to provide further evidence that B56, $\mathrm{W} 1$ and $\mathrm{AF} 3$ are responsive to NFs, we studied whether or not they could achieve certain steps of cortical cell differentiation. For this, roots were spot-inoculated with GMI6526 in the region of root hair emergence, the zone of the root most susceptible to infection (Bhuvaneswari et al.,
1981). Longitudinal sections revealed $\mathrm{Ccd}$ in the wild type (Fig. 1F) and in the mutants (Fig. 1G,H). Ccd was at a maximum 2 days after inoculation in B56, and 4 days after inoculation in AF3 and W1. According to the definition of meristematic cells given by Timmers et al. (Timmers et al., 1999), a meristem was formed in the wild type 4 days after inoculation (Fig. 1F), but no meristematic cells were observed at this time point in any of the mutants (Fig. 1G,H), nor in B56 7 days after inoculation (data not shown). When B56, W1 and AF3 were inoculated with GMI6702, a S. meliloti strain unable to produce NFs (Table 1), Ccd was not seen, confirming that Ccd induction is dependent on NFs (data not shown).

These results show that we have identified a new phenotypic class of M. truncatula $\mathrm{Nod}^{-}$mutants, which are all defective for infection initiation, but which still respond to NFs by root hair deformations and Ccd.

\section{Definition of a new locus, $H C L$, controlling root hair curling}

The genetic determinism of each mutation was analysed by crossing mutants to a wild-type line of $M$. truncatula, Jemalong, carrying a fusion between the promoter of MtENODI1 and the GUS reporter gene (D. G. Barker, J. L. Pingret, M. Chabaud, E. P. Journet, unpublished results). The constitutive GUS expression of the transgene in leaves and cotyledons was used to confirm that $\mathrm{F}_{1}$ individuals were true hybrids (Catoira et al., 2000). The $\mathrm{Nod}^{+}$phenotype of all the $\mathrm{F}_{1}$ plants and the segregation pattern of the nodulation phenotypes in the $F_{2}$ generations indicate that in each case the Nod $^{-}$character was controlled by a single recessive gene (Table 2). Allelism tests revealed that the three mutants belong to the same complementation group, as all $\mathrm{F}_{1}$ plants were $\mathrm{Nod}^{-}$ (Table 3). Given that the mutants come from different mutagenesis bulks, which were multiplied separately (Penmetsa and Cook, 2000), it can be ruled out that B56, W1 and AF3 are siblings.

B56 was then taken as a representative mutant to perform allelism tests with $\mathrm{Nod}^{-} M$. truncatula mutants representing four recently identified complementation groups: B129 (dmi1), TR25 (dmi2), TRV25 (dmi3) and B85 (nsp) (Sagan et al., 1998; Catoira et al., 2000). All the $\mathrm{F}_{1}$ progeny were Nod $^{+}$, indicating that in each case the $\mathrm{Nod}^{-}$mutations are not allelic (Table 2). $F_{1}$ individuals of all crosses, except that between B56 and TRV25, were selfed and the $\mathrm{Nod}^{+}: \mathrm{Nod}^{-}$distributions in the $\mathrm{F}_{2}$ generations were compatible with $d m i 1, d m i 2$ and nsp not being genetically linked to the $\mathrm{Nod}^{-}$mutation in B56 (Table 2).

These data show that we have identified three mutant alleles of a new M. truncatula locus, called $H C L$, for defective in root hair curling. The three $h c l$ alleles have been designated $h c l-1$ (B56), hcl-2 (W1), hcl-3 (AF3). Interestingly, although all three mutants were blocked early for infection, B56 showed the most defective phenotype, both for root hair deformations and Ccd. Since all mutations are recessive and therefore probably result in loss of function, it is likely that $h c l-1$ is the most severe allele, while $h c l-2$ and $h c l-3$ are leaky alleles.

hcl mutants respond to Nod factors in the epidermis by root hair branching and nodulin gene expression

In order to confirm and quantify the NF responsiveness of hcl mutants, rapid and sensitive epidermal responses to 
Fig. 3. Root hair responses to a $S$. meliloti nodFnodL strain (GMI6630), producing modified Nod factors. Roots were stained for $\beta$-galactosidase activity (to visualise bacteria) 5 (A-D) or 10 (E,F) days after inoculation. (A) Wild-type M. truncatula, showing Hac with enlarged bacterial colonies inside marked root hair curls (arrows) and exaggerated root hair deformations in the form of multiple abortive tip growths and continuous curling (arrowheads). Bar, $40 \mu \mathrm{m}$. (BD) Close-ups of Hac in wild-type plants, showing bacteria protruded inside root hairs (arrow in B). Exaggerated root hair deformations are also shown in B (arrowheads). Bars, $25 \mu \mathrm{m}$ (B), $35 \mu \mathrm{m}$ (C), $30 \mu \mathrm{m}$ (D). (E,F) Plant mutants, showing exaggerated root hair deformations, including multiple abortive tip growth and continuous curling (arrowheads), but no Hac formation. (E) AF3. Bar, $100 \mu \mathrm{m}$. (F) W1. Bar, 70 $\mu \mathrm{m}$.
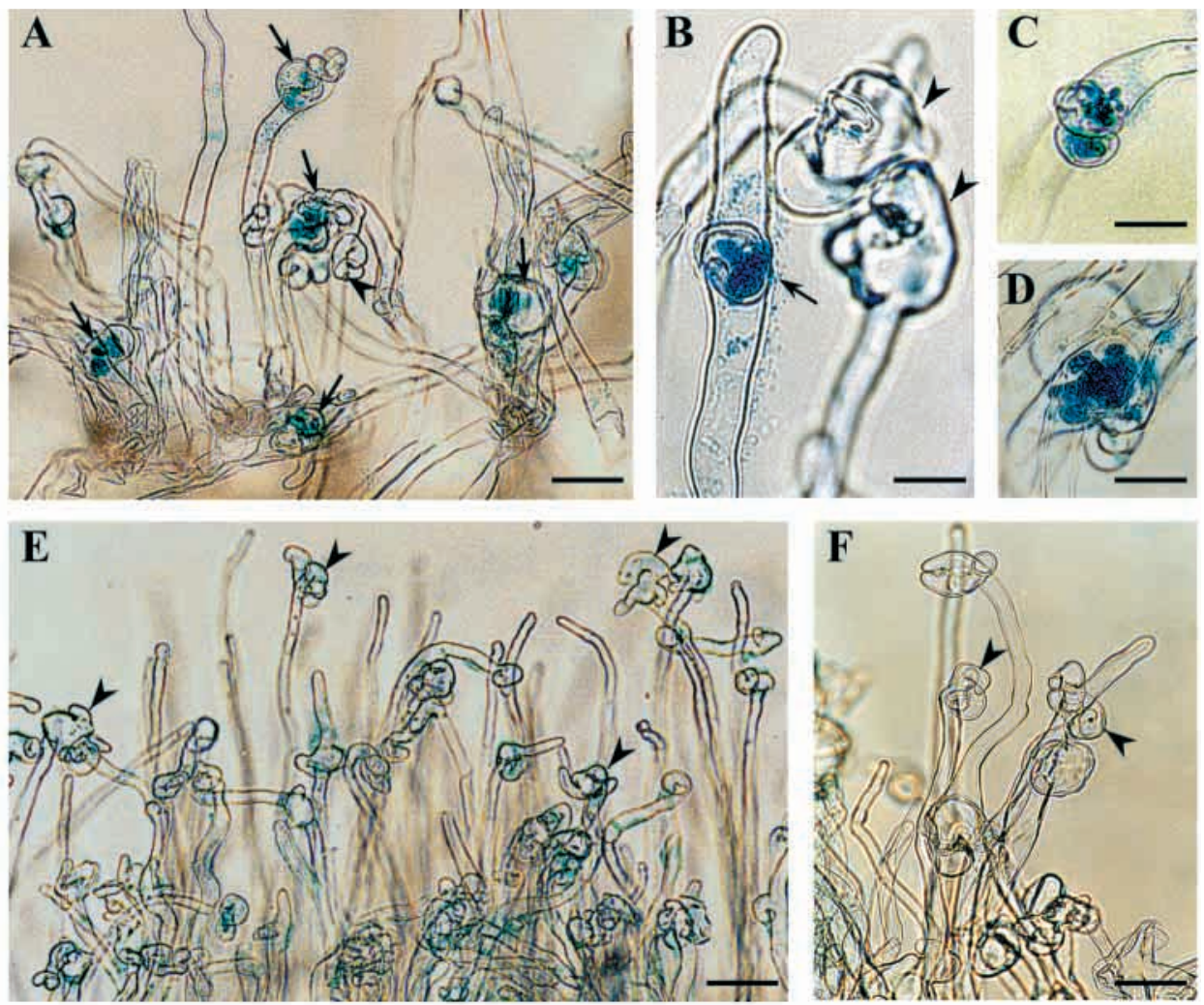

purified NFs were studied in B56. NF-induced root hair branching (Hab) has recently been described in M. truncatula (Catoira et al., 2000). Following treatment of B56 seedlings with $10^{-8} \mathrm{M}$ NFs, Hab was observed that was qualitatively indistinguishable from the wild-type phenotype (data not shown). Furthermore, no significant differences in sensitivity of the response could be detected when plants were treated

Table 2. Inheritance of the $\mathrm{Nod}^{-}$character

\begin{tabular}{|c|c|c|c|c|c|c|c|}
\hline \multirow[b]{2}{*}{ Cross* } & \multirow[b]{2}{*}{ No of crosses } & \multicolumn{2}{|c|}{$\mathrm{F}_{1} \S$, } & \multicolumn{2}{|c|}{$F_{2} \ddagger$} & \multirow[b]{2}{*}{ Expected $* *$} & \multirow[b]{2}{*}{$\chi^{2 * * *}$} \\
\hline & & $\mathrm{Nod}^{+}$ & $\mathrm{Nod}^{-}$ & $\overline{\mathrm{Nod}^{+}}$ & $\overline{\mathrm{Nod}^{-}}$ & & \\
\hline \multirow{2}{*}{ B56×A17II } & $2(1)$ & $9(3)$ & 0 & 109 & 43 & $3: 1$ & 0.88 \\
\hline & & & & 112 & 35 & $3: 1$ & 0.11 \\
\hline \multirow[t]{2}{*}{ AF3×A17I } & 1 & 9 & 0 & 135 & 53 & $3: 1$ & 1.02 \\
\hline & & & & 74 & 18 & $3: 1$ & 1.45 \\
\hline \multirow[t]{2}{*}{ W1×A17I } & 2 & 5 & 0 & 128 & 37 & $3: 1$ & 0.58 \\
\hline & & & & 140 & 36 & $3: 1$ & 1.93 \\
\hline B56×B129 & $2(1)$ & $11(2)$ & 0 & 69 & 51 & $9: 7$ & 0.08 \\
\hline B56×TR25 & $1(3)$ & $2(10)$ & 0 & 93 & 75 & $9: 7$ & 0.05 \\
\hline B56×TRV25 & 2 & 6 & 0 & nd & nd & & \\
\hline & (1) & (2) & 0 & 62 & 37 & $9: 7$ & 1.85 \\
\hline
\end{tabular}

*Pollen donors carried a MtENOD11-GUS fusion construct (see Materials and Methods), used to provide a marker for crosses.

$\S$ Figures in brackets are numbers of additional crosses performed without a marker.

$\ddagger$ Nodulation was scored in plants of the $F_{1}$ and $F_{2}$ generations, 3 weeks after inoculation with $S$. meliloti GMI6526 and numbers represent the number of plants found to be $\mathrm{Nod}^{+}$or $\mathrm{Nod}^{-}$.

**Expectations are based on monogenic $(3: 1)$ or independent $(9: 7)$ segregation of genes.

$* * * P \geq 0.05$ when $\chi^{2} \leq 3.84$

ITThe results scored for two different $\mathrm{F}_{2}$ populations are given. nd=not determined with serial tenfold dilutions of NFs from $10^{-9}$ to $10^{-12} \mathrm{M}$ (data not shown).

Three epidermal nodulin genes were chosen: MtENOD11 (Journet et al., 2001), MtENOD12 (Journet et al., 1994) and ripl (Cook et al., 1995). All three genes are induced within hours of NF treatment in M. truncatula. Firstly, by RT-PCR we found that both MtENODII and ripl transcripts were induced in B56 within 12 hours of addition of $2 \times 10^{-9} \mathrm{M}$ NFs and were more abundant at 48 hours, as for the wild type (Fig. 2A). Results of northern blot analysis confirmed the induction of ripl in B56 (data not shown). Secondly, in order to facilitate the testing of a range of physiological NF concentrations, transgenic lines of B56 were generated for both an MtENOD1 1 promoter-GUS fusion (D. G. Barker, J. L. Pingret, M. Chabaud and E. P. Journet, unpublished results), and an MtENOD12 promoter-GUS fusion (Pingret et al., 1998). In response to serial tenfold NF dilutions $\left(10^{-9}-10^{-12} \mathrm{M}\right)$, GUS activity was localised in root hair and epidermal cells in both mutant and wild-type transgenic lines with the same spatiotemporal pattern (data not shown). Furthermore, no significant differences could be detected in the expression levels of these gene fusions between wild-type and mutant backgrounds (Fig. 2B).

To investigate whether NF recognition had the same structural requirements as in the wild type, the activity of non-sulfated NFs was tested. As previously shown for $M$. truncatula (Catoira et al., 2000; D. G. Barker, J. L. Pingret, M. Chabaud and E. P. Journet, unpublished results), $10^{-9} \mathrm{M}$ nonsulfated NFs were unable to induce either Hab or expression of MtENOD11 in B56 (data not shown).

In $\mathrm{W} 1$ and AF3 neither Hab nor GUS expression in MtENOD11-GUS transgenic plants was different from wildtype plants, in response to $10^{-10} \mathrm{M}$ NFs (data not shown). 
Table 3. Allelism tests

\begin{tabular}{lcccc}
\hline & & & \multicolumn{2}{c}{ Phenotype $\neq$} \\
\cline { 4 - 5 } Female $\left(\mathrm{GUS}^{-}\right)$ & Male $\left(\mathrm{GUS}^{+}\right)^{*}$ & Number of crosses & Nod $^{+}$ & Nod $^{-}$ \\
\hline B56 & AF3 & 3 & 0 & 9 \\
AF3 & B56 & 2 & 0 & 8 \\
B56 & W1 & 2 & 0 & 11 \\
W1 & B56 & 5 & 0 & 15 \\
AF3 & W1 & 1 & 0 & 5
\end{tabular}

*Pollen donors carried a MtENOD11-GUS fusion construct (see Materials and Methods), used to provide a marker for crosses.

†The nodulation phenotype was scored in the $\mathrm{F}_{1}$ generation, 3 weeks after inoculation with $S$. meliloti GMI6526. Numbers represent the number of plants found to be $\mathrm{Nod}^{+}$or $\mathrm{Nod}^{-}$.

These results suggest that NF signalling leading to epidermal nodulin gene expression and Hab is unaffected by mutations in $H C L$.

\section{Nod factor-induction of cortical cell divisions is reduced in the $\mathrm{hcl}$ mutant $\mathrm{B} 56$}

NFs are able to induce cell division foci in the inner cortex of cognate legume roots (Truchet et al., 1991; Schultze and Kondorosi, 1998). We quantified NF induction of Ccd in the hcl mutant B56 to determine whether B56 showed altered sensitivity for this response compared to wild-type plants. Seedlings were NF-treated in growth pouches at final concentrations of $10^{-6} \mathrm{M}, 10^{-7} \mathrm{M}, 10^{-8} \mathrm{M}$ and $10^{-9} \mathrm{M}$ and $\mathrm{Ccd}$ foci were counted by microscopical observation 14 days after NF treatment.

Ccd foci were observed on lateral roots of both wild-type and B56 seedlings at the four NF concentrations tested (Table 4). Starch granules were found to accumulate around nuclei of dividing cells, which facilitated the counting of Ccd foci. For both wild-type and B56 plants, significantly $(P=0.05)$ more Ccd foci were detected per lateral root at $10^{-8} \mathrm{M} \mathrm{NFs}$ compared to $10^{-9} \mathrm{M}$ NFs. At the higher NF concentrations tested, no further increase in the number of Ccd foci could be detected, but mitosis regions were more extended, suggesting that the number of Ccd foci may be controlled by the plant in a similar way to that in which nodule number is controlled.

When the hcl mutant B56 was compared to the wild type, no significant $(P=0.01)$ difference was found in the number of lateral roots per plant (data not shown), but between approximately 20 and $40 \%$ less Ccd foci were detected per lateral root in B56 plants: $21 \%$ less at $10^{-6} \mathrm{M}, 32 \%$ less at $10^{-7}$ M, 26\% less at $10^{-8} \mathrm{M}$ and $38 \%$ less at $10^{-9} \mathrm{M}$ (Table 4). Variance analysis of these data showed that significantly $(P=0.01)$ fewer Ccd foci were induced per lateral root in B56 compared to wild-type plants. These results indicate that the $H C L$ gene is required for NF induction of wild-type levels of Ccd foci.

\section{A S. meliloti nodFnodL strain producing modified Nod factors induces exaggerated root hair deformations in $\mathrm{hcl}$ mutants}

A S. meliloti nodFnodL mutant produces NFs lacking the Oacetyl group and $\mathrm{N}$-acylated by a modified fatty acid chain (Ardourel et al., 1994). The study of the symbiotic behaviour of such a mutant in M. sativa revealed that the NF structural requirement for marked root hair curling is more stringent than for the induction of symbiotic responses such as root hair deformations and cortical cell activation (Ardourel et al., 1994). This work also indicated that in the course of normal infection, there is activation of a negative control mechanism exerted by one infection site, that represses the formation of other infection sites. To determine whether NF structural requirements are similar in $M$. truncatula and $M$. sativa and whether the defect in root hair curling and infection in $\mathrm{hcl}$ mutants is due to constitutive activation of this negative mechanism, the symbiotic behaviour of a S. meliloti nodFnodL mutant was studied. The S. meliloti strain GMI6630, which carries a constitutively expressed lacZ construct (Table 1), was used.

On wild-type M. truncatula, GMI6630 effectively induced shepherd's crooks, with the refractile spot characteristic of the Hac phenotype (Fig. 3A). However, hyaline spots (the closed chamber) were more numerous and much larger than those induced by a wild-type $S$. meliloti strain. An unusually large bacterial colony was formed within the enlarged centre of each root hair curl and this colony often seemed to collapse and clusters of rhizobial aggregates appeared to protrude into root hairs (Fig. 3B-D). Formation of infection threads from the centre of the shepherd's crooks was only very rarely observed. These data indicate that in M. truncatula root hair curling resulting in Hac formation, is a less stringent step, in terms of NF structural requirements, than infection thread formation.

In addition to shepherd's crook formation, continuous curling and multiple abortive tip growth of root hairs was also observed (Fig. 3A,B). This indicates that in M. truncatula, as has been previously observed in $M$. sativa, the absence of effective infection is associated with exaggerated root hair deformations, suggesting the existence of a negative control mechanism for root hair deformation in the course of a normal infection, which is not activated by the nodFnodL mutant.

In B56, W1 and AF3, the nodFnodL mutant, GMI6630, also

Table 4. Nod factor induction of cortical cell division (Ccd) foci in wild-type (WT) and B56 plants

\begin{tabular}{lccccc}
\hline & & \multicolumn{4}{c}{ Nod factor concentration } \\
\cline { 3 - 6 } Ccd foci & Plant & $10^{-6} \mathrm{M}$ & $10^{-7} \mathrm{M}$ & $10^{-8} \mathrm{M}$ & $10^{-9} \mathrm{M}$ \\
\hline Number of Ccd foci/plant & WT & $3.90 \pm 1.30$ & $4.64 \pm 1.78$ & $4.21 \pm 2.04$ & $2.37 \pm 0.81$ \\
Number of Ccd foc/lateral root & B56 & $3.10 \pm 1.49$ & $2.86 \pm 1.01$ & $2.48 \pm 1.36$ & $1.42 \pm 0.87$ \\
& WT & $0.56 \pm 0.09^{\mathrm{a}}$ & $0.59 \pm 0.13^{\mathrm{a}}$ & $0.54 \pm 0.12^{\mathrm{a}}$ & $0.34 \pm 0.09^{\mathrm{b}}$ \\
& B56 & $0.44 \pm 0.10^{\mathrm{a}}$ & $0.40 \pm 0.11^{\mathrm{a}}$ & $0.40 \pm 0.14^{\mathrm{a}}$ & $0.21 \pm 0.09^{\mathrm{b}}$
\end{tabular}

Twenty plants were scored for each treatment and values are means, with standard deviations. In B56, no Ccd foci were detected in untreated roots. In wildtype roots, significantly $(P=0.000001)$ more $\mathrm{Ccd}$ foci were detected at $10^{-9} \mathrm{M} \mathrm{NFs}$ compared to untreated roots. Statistical analysis of Ccd foci/lateral root was performed separately for WT and B56 and within each plant type ${ }^{\mathrm{b}}$ values differed significantly $(P=0.05)$ from ${ }^{\mathrm{a}}{ }^{\mathrm{v} a l u e s}$. Analysis of variance was conducted using the $\mathrm{F}$ test. 
induced exaggerated root hair deformations with much multiple abortive tip growth and continuous curling (Fig. 3E,F). The Hac phenotype was never observed on B56 and only occasionally on $\mathrm{W} 1$ and AF3. When all three plant mutants, as well as wild-type plants, were inoculated with GMI3125, a S. meliloti nodFnodL mutant rendered incapable of producing NFs by insertion of a mutation in nodC (Table 1), no $\mathrm{Hac}$ or root hair deformations were observed (data not shown), indicating that these responses require NFs secreted by the rhizobial mutant.

The fact that $h c l$ mutants exhibit the exaggerated response with the nodFnodL mutant and no response with the
nodFnodLnodC mutant is further evidence that mutations in $H C L$ do not alter NF transduction leading to root hair deformation. The HCL gene apparently controls root hair curling either by a mechanism downstream of this pathway or by an independent mechanism. The induction of exaggerated root hair deformations by the $S$. meliloti nodFnodL strain in hcl mutants, also suggests that the defect in curling and infection caused by $h c l$ mutations is not due to constitutive activation of a negative regulatory mechanism. The rare occurrence of the Hac phenotype in $\mathrm{W} 1$ and AF3, but no infection threads, indicates that $H C L$ is required for both $\mathrm{Hac}$ and infection thread formation.
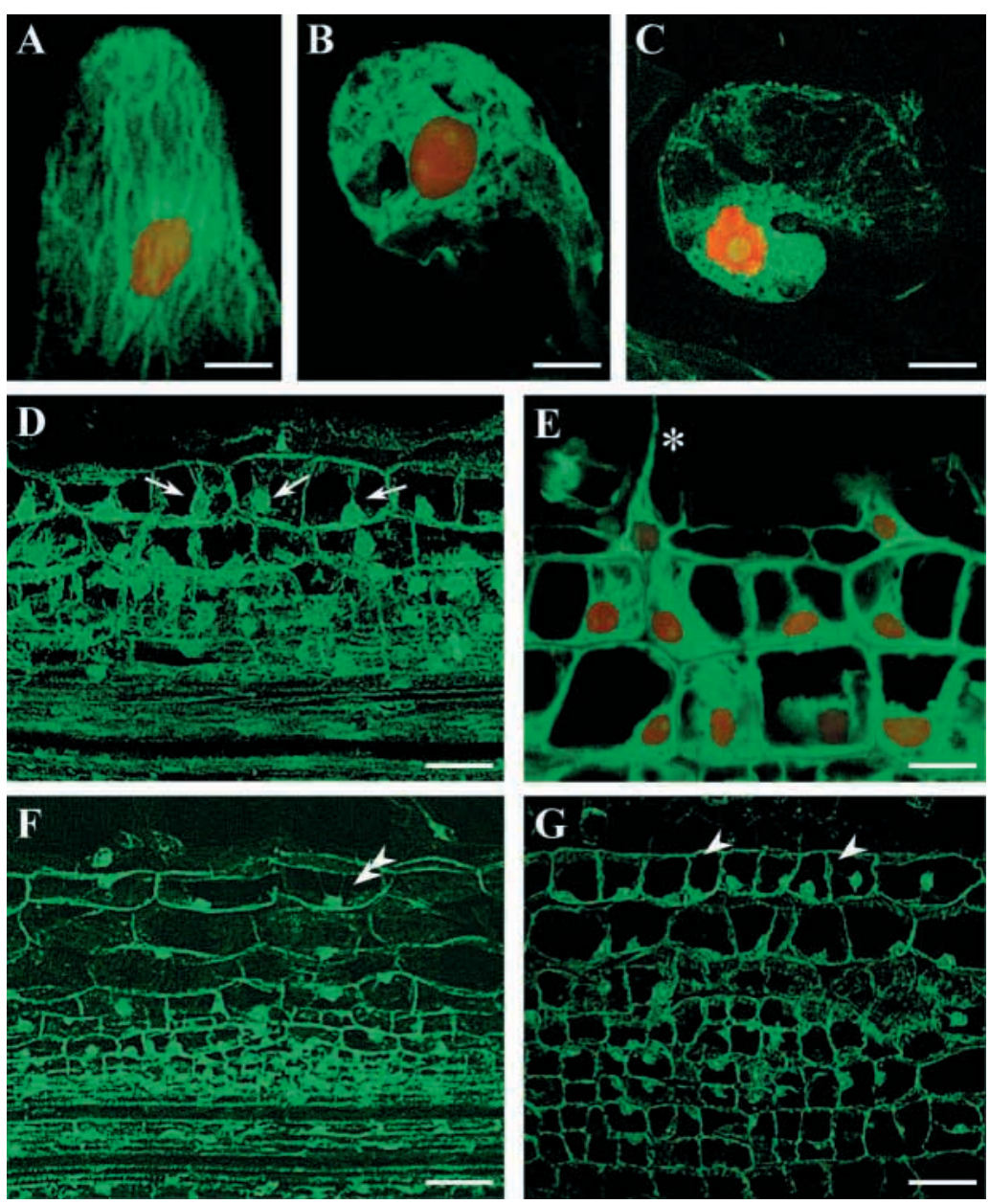

Fig. 4. Rearrangements of microtubules (MTs) in response to S. meliloti. Plants were spot-inoculated, fixed and $\alpha$-tubulin was detected by immunolocalisation. (A-C) Root hairs (A) Wild-type control root hair inoculated with a non-NF producing nodA S. meliloti derivative (GMI6702), showing MTs parallel to the elongation axis of the root hair and an ellipsoid nucleus. Bar, $5 \mu \mathrm{m}$. (B,C) $h c l$ mutant root hair responses to $S$. meliloti GMI6526 2 days after inoculation. (B) B56 mutant, showing a dense array of MTs between the nucleus and the root hair tip (stage II). Bar, $3.5 \mu \mathrm{m}$. (C) W1, showing an asymmetric array of MTs (stage III). Bar, $5.5 \mu \mathrm{m}$. (D-G) Cortical responses to $S$. meliloti GMI6526. (D,E) Wild type, 2 days after inoculation. (D) Nodule primordium in the inner cortex and pre-infection threads (PIT) cells (arrows) in the outer cortex. Bar, 40 $\mu \mathrm{m}$. (E) Infection thread arriving near a PIT (asterisk). Bar, $15 \mu \mathrm{m}$. In A-C and E, nuclei are coloured red. (F) B56, 2 days after inoculation, showing cell divisions in the inner cortex and an activated outer cortical cell (double arrowhead). Bar, $30 \mu \mathrm{m}$. (G) W1, 4 days after inoculation, showing cell divisions (arrowheads) in the outer cortex. Bar, $30 \mu \mathrm{m}$.

\section{Alteration of Rhizobium-induced microtubular reorientation in root hairs of hcl mutants}

The preparation of root hairs for rhizobial infection is associated with microtubule cytoskeleton $(\mathrm{MtC})$ rearrangements (Timmers et al., 1999). To better define the infection block in B56, W1 and AF3, we studied the root hair $\mathrm{MtC}$ by semi-thin sectioning and immunolocalisation of $\alpha$-tubulin. The arrangement of the $\mathrm{MtC}$ in root hairs of $M$. truncatula seedlings, uninoculated or treated with the S. meliloti nodA mutant GMI6702 unable to produce NFs, resembled what has been described in other systems (Miller et al., 1997; Timmers et al., 1999). In growing root hairs both endoplasmic and cortical microtubules (MTs) were found parallel to the elongation axis of the cell and nuclei had an ellipsoid form (Fig. 4A). In mature root hairs, the $\mathrm{MtC}$ was helical and primarily cortical, and uniformly distributed over the entire root hair, while nuclei were flattened against the cell wall (data not shown). In response to rhizobial inoculation, four stages of MtC changes can be distinguished in wildtype $M$. truncatula according to Timmers et al. (1999): (stage I) nuclear activation, ie. a change in form from ellipsoid to round-shaped, and formation of a MtC network around the nucleus; (stage II) migration of the nucleus towards the root hair tip with the formation of a typical endoplasmic MtC network between the nucleus and the tip; (stage III) root hair curling with a progressive remodelling of the endoplasmic MtC network into an asymmetric $\mathrm{MtC}$ array converging to the centre of the curl; and (stage IV) infection site initiation in which the MtC array becomes completely disconnected from the root hair tip and remains exclusively connected to the tip of the infection thread.

Interestingly, despite the absence of shepherd's crooks (see above), changes in MtC organisation were detected in root hairs of B56, AF3 and $\mathrm{W} 1$, corresponding to stages I and II (Fig. 4B). Phenotypically, no differences were observed between wild-type plants and the three mutants in the organisation of the formed endoplasmic $\mathrm{MtC}$ network typical for root hairs preparing for infection. The finding that B56 is blocked for the formation of an asymmetric MtC array, is consistent with the absence of root hair curling in this mutant. Very 
rarely in $\mathrm{W} 1$ and $\mathrm{AF} 3$, root hairs were observed that were apparently arrested between stages II and III (Fig. 4C). This rare presence of asymmetric $\mathrm{MtC}$ arrays, is consistent with the observation that root hairs of $\mathrm{W} 1$ and AF3 are occasionally capable of continuous curling (see Fig. 1E). However, it should be emphasised that the typical convergence of MTs to the future infection site (stage IV), was never observed in AF3 and W1.

These results indicate that $h c l$ mutants respond to rhizobia by rearrangement of the $\mathrm{MtC}$ in root hairs, but only exhibit the first stages of MtC rearrangements typical of wild-type plants. Since B56 appears to carry the most severe hcl allele, we can conclude that $H C L$ controls an asymmetric organisation of the $\mathrm{MtC}$ and the induction of marked root hair curling.

\section{Alteration of $\boldsymbol{R h i z o b i u m - i n d u c e d ~ m i c r o t u b u l a r ~}$ reorientation in cortical cells of $\mathbf{h c l}$ mutants}

The degree of cortical cell activation of the three mutants in the presence of rhizobia (see Fig. 1F,G), was studied in more detail. Compared to wild-type plants (Fig. 4D,E) only limited cell divisions were induced in $h c l$ mutants (Fig. 4F,G). In B56, mitotic activation was generally restricted to a few cell divisions in the pericycle and the inner cortex (Fig. 4F). In the middle and occasionally in the outer cortex of B56, activated cells, in which the nucleus swelled and became central in the cell, accompanied by cytoplasmic strands radiating out from the nucleus ('isodiametric cells'), were detected 2 days after inoculation. At 7 days, occasional divided cells were detected, but no sign of cell activation was observed (data not shown). In AF3 and $\mathrm{W} 1$, isodiametric cells and Ccd were observed in the inner, middle and outer cortex and reached a maximum 4 days after inoculation (Fig. 4G). These data show that outer cortical cells can be activated by rhizobia in all three mutants.

Cellular structures known as cytoplasmic bridges or pre-infection threads (PITs), which join the inner and outer periclinal cell walls of outer cortical cells, have been described in pea, vetch and $M$. sativa (van Brussel et al., 1992; Timmers et al., 1999). The formation of PITs indicates the development of polarity in outer cortical cells and they represent a cellular marker of plant preparation for infection (Timmers et al., 1999). Immunolocalisation of $\alpha$-tubulin coupled to DAPI staining was employed to look for PIT formation following rhizobial inoculation. Two stages in PIT formation could be distinguished in the wild type: (1) cells become activated to the stage of isodiametric cells; (2) cells become polarised with the formation of an anticlinal cytoplasmic bridge containing the MtC organised into parallel strands and surrounding the nucleus positioned against the inner periclinal wall. In wild-type plants, numerous PITs were visible in the outer root cortex 2 days after inoculation (Fig. $4 \mathrm{D}, \mathrm{E})$, often oriented towards an infection thread in a nearby root hair (Fig. 4E). Moreover, PIT-containing cells were very often found to have divided at least once, as previously described in $M$. sativa (Timmers et al., 1999). In contrast, no PITs could be detected in any of the hcl mutants at 2 or 4 days after inoculation (Fig. 4F,G). Instead, only isodiametric or divided cells were observed, indicating that activation of the outer cortex took place followed by cell division, but not by PIT formation as in the wild type.

The ability of the NF-overproducing strain, GMI6390, to induce cortical cell activation and PIT formation was studied in B56. As was the case in wild-type plants, Ccd was enhanced in B56 2 days after inoculation with GMI6390 compared to inoculation with a wild-type $S$. meliloti strain, GMI6526 (data not shown). However, 7 days after inoculation (1) no isodiametric or meristematic cells were detected, indicating that mitotic activity was still transient in B56, and (2) no rhizobia-induced polarity changes in cortical cells (PIT formation) were observed.

Thus, responses that can be elicited by purified NFs, such as root hair deformations (see previous results) and $\mathrm{Ccd}$, were increased in hcl mutants in the presence of NF-overproducing strains, but, in contrast, infection-related responses such as shepherd's crook (see previous results) and PIT formation could not be restored, suggesting that the infection defects in these mutants were not due to decreased NF sensitivity. The absence of PITs in hcl mutants suggests that HCL is required

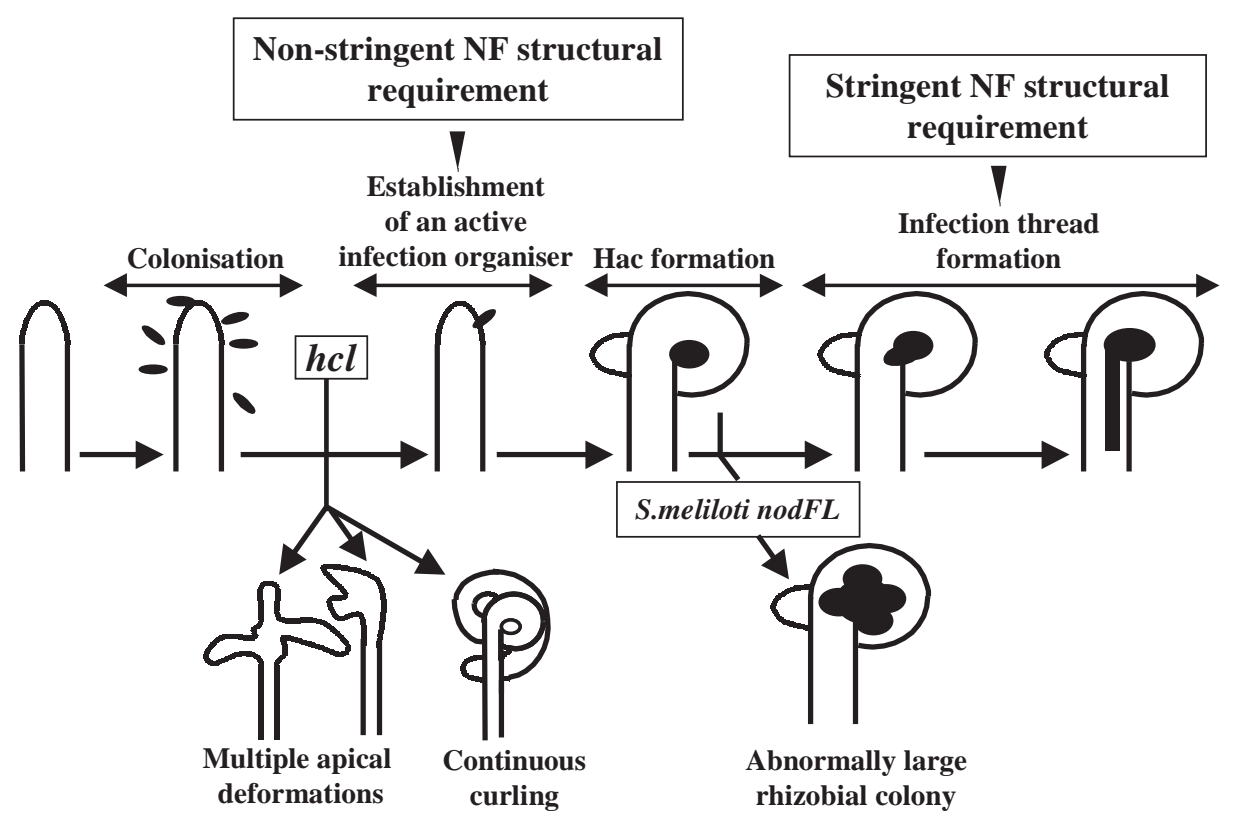

Fig. 5. Model for root hair infection in the Sinorhizobium meliloti-Medicago truncatula symbiosis, in which it is predicted that the M. truncatula $H C L$ gene intervenes between colonisation and establishment of an active infection organiser. The phenotypes of hcl mutants in response to wild-type $S$. meliloti are shown (multiple apical deformations and continuous curling). The phenotype of wild-type $M$. truncatula plants in response to a S. meliloti nodFL mutant producing modified NFs is also shown (abnormally large bacterial colony in curled root hairs). The fact that the $S$. meliloti nodFL mutant is able to induce Hac formation, but not infection thread initiation, indicates that the establishment of an active infection organiser has a non-stringent NF structural requirement (with respect to the acetyl group and fatty acid chain), while infection thread formation has a stringent NF structural requirement. 
for polarisation of outer cortical cells, including re-orientation of the MtC network.

\section{DISCUSSION}

We have used a combination of plant (M. truncatula) and rhizobial $(S$. meliloti) mutants to initiate the genetic dissection of one of the earliest steps of symbiotic infection, root hair curling. Using three $M$. truncatula mutants, we have identified a gene, named $H C L$, which is required for rhizobia-induced root hair curling and infection. During the mutant screen, two more mutants were identified that were blocked early for infection, but still responded to NFs. These mutants are allelic to the three hcl mutants described here (data not shown), implying that few genes are involved in the curling process.

Many mutants of pea, alfalfa, Melilotus albus and Lotus japonicus have already been isolated that are defective for root hair curling, but detailed studies aimed at characterising the plant defects responsible are scarce. In certain cases, mutant NF responsiveness has been tested, revealing that one genetic locus of pea, SYM8, controls PSENOD5 and PsENOD12A gene expression in response to NFs (Albrecht et al., 1998), whereas Rhizobium-induced expression of PSENOD12A has been shown to be abolished by mutation of sym19 of pea (Schneider et al., 1999). In alfalfa, the mutant MN-NN1008 is deficient for calcium spiking in response to NFs (Ehrhardt et al., 1996) and mutations affecting three pea genes have recently also been found to abolish NF-induced calcium spiking (Walker et al., 2000). A genetic locus of $L$. japonicus, NIN, is required for the formation of infection threads and, like $h c l$ mutants, nin mutants display root hair deformations, indicating that NIN is not involved in early NFdependent signal exchange (Schauser et al., 1999). However, unlike $h c l$ mutants, nin mutants are completely deficient for rhizobia-induced cell divisions, indicating that NIN and $H C L$ control different functions. Finally, a sym 7 mutant of pea, E69, has a similar phenotype to hcl mutants, showing root hair deformations, but no root hair curling in response to Rhizobium. Interestingly, in response to NFs, E69 shows a normal calcium spiking response, as does the $h c l$ mutant B56 (Walker et al., 2000; Wais et al., 2000).

In $M$. truncatula, the recent analysis of $\mathrm{Hac}^{-}$mutants led to the identification of four genes (DMI1, DMI2, DMI3, NSP), mutations in which cause pleiotropic defects in NF responses, consistent with these genes being required for NF transduction (Catoira et al., 2000; Wais et al., 2000). Here, we describe the HCL gene of M. truncatula, mutants in which are also $\mathrm{Hac}^{-}$, but for which several lines of evidence indicate that the block is not due to a defect in NF responsiveness in the epidermis: (i) NF induction of root hair branching is normal; (ii) $\mathrm{NF}$ induction of transcription of the early nodulin genes MtENOD11, MtENOD12 and ripl has an unchanged spatiotemporal pattern compared to wild-type plants; (iii) rhizobial strains that overproduce NFs stimulate root hair deformation, but do not elicit marked root hair curling; (iv) exaggerated root hair deformations, as for wild-type plants, are exhibited in response to a nodFnodL rhizobial mutant; (v) NFs can induce calcium spiking in root hairs of B56 (Wais et al., 2000). While epidermal NF transduction appears to be unaffected in hcl mutants, results of NF induction of Ccd foci indicate that $h c l$ mutations slightly decrease either the efficiency of NF transduction to cortical cells or cortical cell responsiveness to NFs.

hcl mutants therefore show a novel phenotype among $\mathrm{Nod}^{-}$ mutants: uncoupling epidermal NF responses, which are still induced, from infection, which is blocked at a very early stage, and Ccd, which is not induced at wild-type levels. Furthermore, hcl mutations appear to specifically affect infection by rhizobia, as hcl mutants are still able to form an effective association with endomycorrhizal fungi (M. Harrison, personal communication; data not shown). Some infection defects in variants of pea, soybean and clover are controlled by gene-forgene interactions involving rhizobial nod genes (Heidstra and Bisseling, 1996). We were unable to find rhizobial strains able to overcome the nodulation defects caused by hcl mutations (data not shown), but cannot exclude that such strains exist.

To determine the function of the HCL product, a prerequisite is to isolate the HCL gene. The necessary tools are now available in $M$. truncatula for the positional cloning of genes (Cook, 1999) and $h c l$ is being mapped on the M. truncatula genetic map.

\section{hcl mutants are unable to reorient the microtubular cytoskeleton network in response to rhizobia}

A recent study of $M$. truncatula mutants led us to hypothesise that a NF transduction pathway in root hairs has a dual role in root hair curling: to inhibit the endogenous tip growth of root hairs and to elicit a novel NF-dependent tip growth (Catoira et al., 2000). The inability of $\mathrm{hcl}$ mutants to form marked root hair curls is apparently not due to a defect in this NF transduction pathway, since NF induction of Hab is normal in hcl mutants. However, in temperate legumes such as Medicago sp., pea and vetch, the addition of purified NFs alone only triggers root hair deformation and branching, while the presence of NF-producing rhizobia is required in these legumes for marked root hair curling (Fellay et al., 1995). This indicates that bacterial factor(s) other than NFs or positional information is required for Hac formation.

The change in direction of root hair tip growth during curling requires the formation of a 'proper infection site' (Van Batenburg et al., 1986; Kijne, 1992), also called a 'new centre of influence' (Emons and Mulder, 2000). Numerous rhizobial cells or microcolonies can attach to a single root hair, but only one curl is formed suggesting that the influence of only one particular microcolony becomes dominant and dictates the position of the curling site (Van Batenburg et al., 1986; Kijne, 1992). By studying the MtC of root hairs of $M$. truncatula during the curling process, it was found that an axial asymmetry is created with the MtC network migrating towards the centre of the curl (stage III). This suggests that the selected rhizobial microcolony has established a signalling centre, that provides positional cues to direct the re-orientation of the $\mathrm{MtC}$ network at the root hair tip. We propose to call this signalling centre the 'infection organiser', by analogy to the organiser concept developed in vertebrates (Lemaire and Kodjabachian, 1996) (Fig. 5). By infection organiser we mean the selected rhizobial microcolony, together with the signals it produces (NFs and possibly others) and plant components involved in perceiving and transducing these signals. Once established, the infection organiser signals the information to the $\mathrm{MtC}$ that an appropriate NF-producing microcolony is present and the $\mathrm{MtC}$ 
responds by becoming re-directed, preparing the root hair for infection.

Root hairs of mutant B56 were activated by rhizobia, exhibiting a MtC re-organisation resembling that induced by purified NFs in M. sativa (A. C. J. T., unpublished results). However, the MtC network was not re-orientated in an asymmetrical way. W1 and AF3 occasionally exhibited an asymmetrical MtC organisation, probably because these mutants carry leaky $\mathrm{hcl}$ alleles. These results indicate that $\mathrm{HCL}$ is required either to form the infection organiser or to recognise and translate the positional information provided by rhizobia for the infection organiser to be active, and the failure to do so probably results in the multiple root hair deformations which characterise hcl mutants (Fig. 5).

Cortical cells underlying infected root hairs are also activated and differentiate to pave the way for symbiotic infection. In $M$. sativa, unlike in vetch (van Brussel et al., 1992), NFs alone are not sufficient to trigger PIT formation, which instead requires the presence of specific NF-producing rhizobia (Timmers et al., 1999). This requirement suggests, as in the case of root hair curling, either the role of an additional bacterial factor or of a NF-producing microcolony. That positional information is involved in PIT formation in $M$. truncatula is suggested by the fact that PITs are often oriented towards infection threads in nearby root hairs. We propose that, in addition to controlling root hair curling, the infection organiser also controls the polarity changes associated with PIT formation in cortical cells. The infection organiser is thus responsible for signalling to the cytoskeleton to make polarity changes necessary for infection, both in root hair and cortical cells.

All three $h c l$ mutants exhibited cortical cell activation, but not the novel polarity resulting in PIT formation. There are two possible hypotheses to account for this failure: (i) a functional infection organiser is not formed and therefore the positional cues are not provided; (ii) the positional cues are produced, but hcl mutants are unable to respond to this positional signalling. Both possibilities lead to the same conclusion reached from analysis of the root hair MtC; that HCL is needed to establish an active infection organiser (Fig. 5).

In $M$. sativa, PIT formation is induced by a rhizobial exo mutant producing abortive infection threads, but not by a rhizobial nodFnodL mutant unable to induce Hac formation (Timmers et al., 1999). Future studies of PIT formation in $M$. truncatula with bacterial and plant mutants able to form shepherd's crooks or which initiate the formation of abortive infection threads should determine whether the chamber in the centre of the curl enclosing the rhizobial microcolony or the growing tips of infection threads are needed to provide positional cues for cortical cell polarisation.

The Rhizobium-legume symbiosis is an interesting system to study the induction of cell polarity in plants, providing the following advantages. (i) The facultative induction of cell polarity in root hair and cortical cells enables the isolation of (non-lethal) mutants. (ii) The signalling centres that provide the positional cues for cellular and cytoskeletal reorganisation are easily identifiable as a bacterial microcolony, in the centre of a root hair curl. (iii) The signalling source is a bacterium which can be finely dissected using genetics to generate subtle modifications of the signals. (iv) The bacterial signalling molecules are NFs which have specific effects on cytoskeleton reorganisation and on the expression of the plant symbiotic program, but do not exhibit general toxic activities, in contrast to drugs used to study cytoskeleton dynamics. This system should thus provide tools to identify the genes, signals and mechanisms involved in the establishment of cell polarity via spatial reorganisation of the cytoskeleton (Miller et al., 1997; Kropf et al., 1998; Yang, 1998). In addition to the MtC, changes to the actin cytoskeleton are also associated with early stages of the Rhizobium-legume symbiosis (Cárdenas et al., 1998; Miller et al., 1999; de Ruijter et al., 1999). Constructs consisting of cytoskeleton-binding elements fused to reporter genes (Ludin and Matus, 1998; Kost et al., 1999) should facilitate future studies associating the genetic dissection of both partners with detailed studies of the cytoskeleton reorganization induced in host cells during rhizobial infection.

\section{In M. truncatula, Nod factor structural requirements for root hair curling and infection thread initiation are different}

In M. truncatula, unlike in M. sativa (Ardourel et al., 1994), a $S$. meliloti nodFnodL mutant induces the formation of genuine shepherd's crooks, with a hyaline spot, from which, however, only very rare infection threads are formed. This indicates that in $M$. truncatula the NF structural requirement is more stringent for the initiation of infection thread formation than for the formation of the marked curling (Fig. 5). A similar finding has recently been reported in vetch and pea (Walker and Downie, 2000). This difference in NF stringency suggests that plant components of the infection organiser involved in NF recognition are different in the mechanisms for hair curling and in those for the formation of infection threads. The putative plant determinants required for formation of infection threads and having a stringent NF requirement, represent potential NF 'entry' receptors (Ardourel et al., 1994).

With the nodFnodL mutant, the chamber located in the centre of the marked curl, and visible as a hyaline spot, contains an unusually large number of bacteria and, in many cases, bacteria appear to protrude into the cytoplasm of the root hair. Large accumulations of bacteria are also seen on vetch and pea, forming aberrant infection foci, with a rhizobial strain producing NFs lacking the O-acetyl group and acylated by a modified fatty acid chain (Walker and Downie, 2000). We can hypothesise that mutant bacterial cells, producing inappropriate NFs, are unable to 'open the legume door' and form an infection thread initiation site (Relic et al., 1994). Being trapped in the closed chamber (Callaham and Torrey, 1981), in the absence of an originating thread, they multiply and become more numerous than normal. The pressure in the closed chamber consequently increases and, the cell wall probably being partly degraded, bacteria can protrude by 'housebreaking' into the root hair cytoplasm. These observations are consistent with the hypothesis of Turgeon and Bauer (1985) that a primary function of root hair curling is to entrap rhizobia so that bacterial multiplication forces them inward against host cell turgor.

We are very grateful to David Barker and Etienne Journet for providing transgenic $M$. truncatula and the MtENODII sequence before publication, to Pascal Gamas for the cortical cell division assay protocol, and to Marie-Christine Auriac for her technical assistance in studying the microtubule cytoskeleton. Romy Catoira and Christine 
Galera received Ph.D fellowships from the French Ministère de l'Enseignement Supérieur et de la Recherche. Financial support for the project was provided by the Human Frontier Science Program Organization (RG0327/1998-M), by the Centre National de la Recherche Scientifique (Genome programme 1998-2000) and the Institut National de la Recherche Agronomique (Genomes and Functions programme 1998-1999).

\section{REFERENCES}

Albrecht, C., Geurts, R., Lapeyrie, F. and Bisseling, T. (1998). Endomycorrhizae and rhizobial Nod factors both require SYM8 to induce the expression of the early nodulin genes PsENOD5 and PSENOD12A. Plant J. 15, 605-614.

Ardourel, M., Demont, N., Debellé, F., Maillet, F., De Billy, F., Promé, J. C., Dénarié, J. and Truchet, G. (1994). Rhizobium meliloti lipooligosaccharide nodulation factors: Different structural requirements for bacterial entry into target root hair cells and induction of plant symbiotic developmental responses. Plant Cell 6, 1357-1374.

Bakhuizen, R. (1988). The plant cytoskeleton in the Rhizobium-legume symbiosis. PhD Thesis. Leiden University, The Netherlands.

Bekki, A., Trinchant, J. C. and Rigaud, J. (1987). Nitrogen fixation $\left(\mathrm{C}_{2} \mathrm{H}_{2}\right.$ reduction) by Medicago nodules and bacteroids under sodium chloride stress. Plant Physiol. 71, 61-67.

Bhuvaneswari, T. V., Bhagwat, A. A. and Bauer, W. D. (1981). Transient susceptibility of root cells in four common legumes to nodulation by Rhizobia. Plant Physiol. 68, 1144-1149.

Brewin, N. J. (1998). Tissue and cell invasion by Rhizobium: the structure and development of infection threads and symbiosomes. In The Rhizobiaceae, molecular biology of model plant-associated bacteria. (ed. H.P. Spaink, Kondorosi A. and Hooykaas P.J.J.), pp. 417-429. Dordretch: Kluwer Academic Publishers.

Callaham, D. A. and Torrey, J. G. (1981). The structural basis for infection of root hairs of Trifolium repens by Rhizobium. Can. J. Bot. 59, 16471664.

Catoira, R., Galera, C., De Billy, F., Penmetsa, R. V., Journet, E. P., Maillet, F., Rosenberg, C., Cook, D., Gough, C. and Dénarié, J. (2000) Four genes of Medicago truncatula controlling components of a Nod factor transduction pathway. Plant Cell 12, 1647-1666.

Cárdenas, L., Vidali, L., Dominguez, J., Perez, H., Sanchez, F., Hepler, P.K. and Quinto, C. (1998). Rearrangement of actin microfilaments in plant root hairs responding to Rhizobium etli nodulation signals. Plant Physiol. 116, 871-877.

Cook, D., Dreyer, D., Bonnet, D., Howell, M., Nony, E. and Vandenbosch, K. (1995). Transient induction of a peroxidase gene in Medicago truncatula precedes infection by Rhizobium meliloti. Plant Cell 7, 43-55.

Cook, D. R. (1999). Medicago truncatula-a model in the making! Curr. Opin. Plant. Biol. 2, 301-304.

Dart, P. J. (1977). Infection and development of leguminous nodules. In $A$ treatise on dinitrogen fixation (ed. R.W.F. Hardy), pp. 367-472. New-York: Wiley.

Debellé, F., Rosenberg, C., Vasse, J., Maillet, F., Martinez, E., Dénarié, J. and Truchet, G. (1986). Assignment of symbiotic developmental phenotypes to common and specific nodulation (nod) genetic loci of Rhizobium meliloti. J. Bacteriol. 168, 1075-1086.

Demont, N., Ardourel, M., Maillet, F., Promé, D., Ferro, M., Promé, J-C. and Dénarié, J. (1994). The Rhizobium meliloti regulatory nodD3 and syrM genes control the synthesis of a particular class of nodulation factors $\mathrm{N}$ acylated by $(\omega-1)$-hydroxylated fatty acids. EMBO J. 13, 2139-2149.

Dénarié, J., Debellé, F. and Promé, J. C. (1996). Rhizobium lipochitooligosaccharide nodulation factors: signaling molecules mediating recognition and morphogenesis. Aпnи Rev Biochem 65, 503-535.

de Ruijter, N.C.A., Bisseling, T. and Emons, A. M. C. (1999). Rhizobium Nod factors induce an increase in sub-apical fine bundles of actin filaments in Vicia sativa root hairs within minutes. Mol. Plant-Microbe Interact. 12, 829-832.

Downie, J. A. (1998). Functions of Rhizobial nodulation genes. In The Rhizobiaceae, molecular biology of model plant-associated bacteria. (ed. H.P. Spaink, Kondorosi A. and Hooykaas P.J.J.), pp. 387-402. Dordretch: Kluwer Academic Publishers.

Downie, J. A. and Walker, S. A. (1999). Plant responses to nodulation factors. Curr. Opin. Plant. Biol. 2, 483-489.
Ehrhardt, D. W., Wais, R. and Long S. R. (1996). Calcium spiking in plant root hairs responding to Rhizobium nodulation signals. Cell 85, 673681.

Emons, A. M. and Mulder, B. (2000). Nodulation factors trigger an increase of fine bundles of subapical actin filaments in Vicia root hairs: implications for root hair curling around bacteria. In Biology of Plant-Microbe Interactions Vol.2 (ed. P.J.G.M. de Wit, Bisseling T. and Stiekema W.), pp. 272-276. Minnesota: International Society for Molecular Plant-Microbe Interactions.

Fellay, R., Rochepeau, P., Relic, B. and Broughton, W. J. (1995). Signals to and emanating from Rhizobium largely control symbiotic specificity. In Pathogenesis and host specificity in plant diseases. Histopathological, biochemical, genetic and molecular bases. (ed. U.S. Singh, Singh R.P. and Kohmoto K.), pp. 199-220. Oxford: Pergamon/Elsevier Science Ltd.

Hadri, A. E. and Bisseling, T. (1998). Responses of the plant to Nod factors. In The Rhizobiaceae, molecular biology of model plant-associated bacteria. (ed. H.P. Spaink, Kondorosi A. and Hooykaas P.J.J.), pp. 403-416. Dordretch: Kluwer Academic Publishers.

Heidstra, R. and Bisseling, T. (1996). Nod factor-induced host responses and mechanisms of Nod factor perception. New Phytol. 133, 25-43.

Honma, M.A., Asomaning, M. and Ausubel, F.M. (1990). Rhizobium meliloti nodD genes mediate host-specific activation of nodABC. $J$. Bacteriol. 172, 901-911.

Journet, E. P., Pichon, M., Dedieu, A., De Billy, F., Truchet, G. and Barker, D. G. (1994). Rhizobium meliloti Nod factors elicit cell-specific transcription of the ENOD12 gene in transgenic alfalfa. Plant J. 6, 241-249.

Journet, E. P., El-Gachtouli, N., Vernoud, V., de Billy, F., Pichon, M., Dedieu, A., Arnould, C., Morandi, D., Barker, D. and GianinazziPearson, V. (2001). Medicago truncatula ENOD11: a novel RPRP-encoding early nodulin gene expressed during mycorrhization in arbuscule-containing cells. Mol. Plant-Microbe Interact. In press.

Kendall, M. G. and Stuart, A. (1976). The advanced theory of statistics. Charles Griffin Ltd, London.

Kijne, J. W. (1992). The Rhizobium infection process. In Biological Nitrogen Fixation. (ed. G. Stacey, Burris R.H. and Evans H.J.), pp. 349-398. New York: Chapman and Hall.

Kost, B., Mathur, J. and Chua, N. H. (1999). Cytoskeleton in plant development. Curr. Opin. Plant. Biol. 2, 462-470.

Kropf, D. L., Bisgrove, S. R. and Hable, W. E. (1998) Cytoskeletal control of polar growth in plant cells. Curr. Opin. Plant. Biol. 10, 117-122.

Lemaire, P. and Kodjabachian, L. (1996). The vertebrate organizer: structure and molecules. Trends Genet. 12, 525-531.

Lerouge, P., Roche, P., Faucher, C., Maillet, F., Truchet, G., Promé, J. C. and Dénarié, J. (1990). Symbiotic host-specificity of Rhizobium meliloti is determined by a sulphated and acylated glucosamine oligosaccharide signal. Nature 344, 781-784.

Leong, S. A., Williams, P. H. and Ditta, G. S. (1985). Analysis of the $5^{\prime}$ regulatory region of the gene for $\delta$-aminolevulinic acid synthetase of Rhizobium meliloti. Nucl. Acids Res. 13, 5965-5976.

Long, S. R. (1996). Rhizobium symbiosis: Nod factors in perspective. Plant Cell 8, 1885-1898.

Ludin, B. and Matus, A. (1998). GFP illuminates the cytoskeleton. Trends Cell Biol. 8, 72-77.

Miller, D. D., de Ruijter N. C. A. and Emons, A. M. (1997). From signal to form: aspects of the cytoskeleton-plasma membrane-cell wall continuum in root hair tips. J. Exp. Bot. 48, 1881-1896.

Miller, D. D., de Ruijter, N. C. A., Bisseling, T. and Emons, A. M. C. (1999). The role of actin in root hair morphogenesis: studies with lipochitooligosaccharidde as a growth stimulator and cytochalasin as an actin perturbing drug. Plant J. 17, 141-154.

Mylona, P., Pawlowsk, K. and Bisseling, T. (1995). Symbiotic nitrogen fixation. Plant Cell 7, 869-885.

Penmetsa, R. V. and Cook, D. R. (1997). A legume ethylene-insensitive mutant hyperinfected by its rhizobial symbiont. Science 275, 527-530.

Penmetsa, R. V. and Cook, D. R. (2000) Production and characterization of diverse developmental mutants of Medicago truncatula. Plant Physiol. 123, 1387-1397.

Pingret, J. L., Journet, E. P. and Barker, D. G. (1998). Rhizobium Nod factor signaling. Evidence for a $G$ protein-mediated transduction mechanism. Plant Cell 10, 659-672.

Relic, B., Perret, X., Estrada-Garcia, M. T., Kopcinska, J., Golinowski, W., Krishnan, H. B., Pueppke, S. G. and Broughton, W. J. (1994). Nod factors of Rhizobium are a key to the legume door. Mol. Microbiol. 13, 171178. 
Ridge, R. W. and Rolfe, B. G. (1985). Rhizobium sp. degradation of legume root hair cell wall at the site of infection thread origin. Appl. Environ. Microbiol. 50, 717-720.

Roche, P., Lerouge, P., Ponthus, C. and Promé, J. C. (1991). Structural determination of bacterial nodulation factors involved in the Rhizobium meliloti-alfalfa symbiosis. J. Biol. Chem. 266, 10933-10940.

Sagan, M., Morandi, D., Tarenghi, E. and Duc, G. (1995). Selection of nodulation and mycorrhizal mutants in the model plant Medicago truncatula (Gaertn) after gamma-ray mutagenesis. Plant Sci. 111, 63-71.

Sagan, M., de Larambergue, H. and Morandi, D. (1998). Genetic analysis of symbiosis mutants in Medicago truncatula. In Biological nitrogen fixation for the 21st Century. C. Elmerich, A. Kondorosi, and W.E.Newton, ed. (Kluwer Academic Publishers), p.317-318.

Schauser L., Roussis A., Stiller J. and Stougaard J. (1999). A plant regulator controlling development of symbiotic root nodules. Nature $\mathbf{4 0 2}$, 191-195.

Schneider, A., Walker, S. A., Poyser, S., Sagan, M., Ellis, T. H. N. and Downie, J. A. (1999). Genetic mapping and functional analysis of a nodulation-defective mutant (sym19) of pea (Pisum sativum L.). Mol. Gen. Genet. 262: 1-11.

Schultze M. and Kondorosi A. (1998). Regulation of symbiotic root nodule development. Annu. Rev. Genet. 32, 33-57.

Timmers, A. C., Auriac, M. C. and Truchet, G. (1999). Refined analysis of early symbiotic steps of the Rhizobium-Medicago interaction in relationship with microtubular cytoskeleton rearrangements. Development 126, 36173628.

Truchet, G., Roche, P., Lerouge, P., Vasse, J., Camut, S., De Billy, F., Promé, J. C. and Dénarié, J. (1991). Sulphated lipo-oligosaccharide signals of Rhizobium meliloti elicit root nodule organogenesis in alfalfa. Nature 351, 670-673.

Truchet, G., Debellé, F., Vasse, J., Terzaghi, B., Garnerone, A. M., Rosenberg, C., Batut, J., Maillet, F. and Dénarié, J. (1985). Identification of a Rhizobium meliloti pSym2011 region controlling the host specificity of root hair curling and nodulation. J. Bacteriol. 164, 1200-1210.

Turgeon, B. G. and Bauer, W. D. (1985). Ultrastructure of infection thread development during the infection of soybean by Rhizobium japonicum. Planta 163, 328-349.

Van Batenburg, F. H. D., Jonker, R. and Kijne, J. W. (1986). Rhizobium induces marked root hair curling by redirection of tip growth, a computer simulation. Physiol. Plant. 66, 476-480.

Van Brussel, A., Bakhuizen, R., Van Spronsen, P. C., Spaink, H. P., Tak, T., Lugtenberg, B. J. J. and Kijne, J. W. (1992). Induction of pre-infection thread structures in the leguminous host plant by mitogenic Lipooligosaccharides of Rhizobium. Science 257, 70-72.

Van Spronsen, P. C., Bakhuizen, R., van Brussel, A. and Kijne, J. W. (1994). Cell wall degradation during infection thread formation by the root nodule bacterium Rhizobium leguminosarum is a two-step process. Eur. J. Cell. Biol. 64, 88-94.

Wais, R. J., Galera, C., Oldroyd, G., Catoira, R., Penmetsa, R. V., Cook, D., Gough, C., Dénarié, J. and Long, S. R. (2000) Genetic analysis of calcium spiking responses in nodulation mutants of Medicago truncatula. Proc. Natl. Acad. Sci. (USA). 97, 13407-13412.

Walker, S. A. and Downie, J. A. (2000) Entry of Rhizobium leguminosarum biovar viciae into root hairs requires minimal Nod factor specificity, but subsequent infection thread growth requires nodO or nodE. Mol. PlantMicrobe Interact. 13, 754-762.

Walker, S. A., Viprey, V. and Downie, J. A. (2000) Dissection of nodulation signaling using pea mutants defective for calcium spiking induced by Nod factors and chitin oligomers. Proc. Natl. Acad. Sci. (USA). 97, 13413-13418.

Wood, S. M. and Newcomb, W. (1989). Nodule morphogenesis: the early infection of alfalfa (Medicago sativa) root hairs by Rhizobium meliloti. Can. J. Bot. 67, 3108-3122.

Yang, Z. (1998) Signaling tip growth in plants. Curr. Opin. Plant. Biol. 1, $525-$ 530 . 